\title{
Reforma Administrativa de Goiás
}

\section{- UMA EXPERIENCIA PIONEIRA}

JOAQUIM NEVES PEREIRA

\begin{abstract}
Ex-Secretário do Interior e Justiça de Goiás, exChefe da Equipe de Reforma Administrativa daquele Estado e ex-Secretário de Finanças do Govêrno do Distrito Federal. Técnico de Administração do
\end{abstract}

DASP.

Em 1955, fui distinguido com um honroso convite para planejar, dirigir e executar a reforma administrativa de Goiás.

Confesso que relutei em aceitar tal encargo. Como Técnico de Administração do DASP, sem qualquer experiência ou vinculação política, receava que um trabalho de profundidade e de cunho altamente moralizador, como o que eu iria levar a efeito, pudesse ser prejudicado pelas incompreensões e por interêsses políticos contrariados.

Logo após minha chegada àquele Estado, nos meus primeiros contatos com o Governador, verifiquei, para minha tranqüilidade, que eu estava inteiramente equivocado. Sua Excelência não só me prestigiou, por tôdas as formas e em tôdas as oportunidades, como jamais permitiu interferência de qualquer natureza no meu trabalho.

Cônscio da enorme responsabilidade que pesava sôbre meus ombros, minha primeira e maior preocupação foi recrutar uma equipe de funcionários estaduais, escolhidos sem quaisquer considerações de ordem pessoal ou política, mas tendo em vista, exclusivamente, suas qualificações morais, intelectuais e profissionais.

Durante a seleção, submeti os candidatos a rigorosa entrevista, através da qual procurei recolher o maior número de elementos e informações que me habilitassem a formar perfeito juízo sôbre suas reais possibilidades de cooperação num em- 
preendimento da complexidade e amplitude do que iríamos realizar.

De modo geral, minhas preferências recaíram em:

a) funcionários portadores de certificados de cursos ministrados pelo DASP;

b) funcionários possuidores de certificados de conclusão de cursos mantidos pela Escola Brasileira de Administração da Fundação Getúlio Vargas;

c) servidores que concluíram cursos de aperfeiçoamento ministrados por outras instituições oficiais ou particulares;

d) servidores que se destacaram nos diversos setores da administração estadual, quer pela publicação de estudos ou trabalhos técnicos, quer pelo exercício relevante de cargos de direção ou função de chefia;

e) funcionários que, além dos requisitos acima especificados, revelassem senso de responsabilidade, espírito de equipe, alto grau de iniciativa e facilidade em assimilar e interpretar as incumbências que lhes fôssem deferidas.

Organizada a Equipe, minhas atenções se voltaram para 0 seu treinamento, tarefa de que me incumbi pessoalmente, exceto na parte relativa a organização e métodos, que ficou a cargo da Dra. Daysy Passarinho Pereira, Técnico de Administração do DASP e da Fundação Getúlio Vargas.

Encerrando o período de treinamento, quando senti que todos os meus companheiros já se achavam tècnicamente preparados, dei início aos trabalhos da reforma, de acôrdo com - programa preestabelecido, e que em sua estrutura geral compreendia os seguintes trabalhos:

- estudo e levantamento de todos os setores da administração estadual, visando a identificar vícios, falhas e distorções, para aplicação dos corretivos necessários;

- levantamento das rotinas de trabalho nas diferentes unidades administrativas, com o fim de simplificar os métodos e processos de execução, mediante a eliminação das tarefas inúteis ou parasitárias;

- estabelecimento de estrutura racional para a máquina administrativa do Estado;

- codificação e atualização das leis de material; 
- centralização das compras e racionalização das diversas fases da administração de material;

- centralização, em órgão diretamente subordinado ao Governador, das atividades relativas à administração de pessoal e estabelecimento de bases para adoção do sistema do mérito no Estado;

- elaboração de adequado plano de classificação de cargos e de pagamento para os servidores estaduais;

- racionalização da administração financeira e orçamentária;

- reorganização do Departamento de Estradas de Rodagem de Goiás (DER-GO), bem como confecção de implantação do respectivo quadro de pessoal;

- reorganização da Loteria do Estado e estabelecimento de normas reguladoras da distribuição dos lucros por ela obtidos;

- preparação de pessoal especializado para os diferentes setores administrativos do Estado.

Passarei a analisar e comentar, a seguir, os itens constantes do esquema aqui apresentado.

\section{ESTUDOS E LEVANTAMENTOS}

Quem se der ao trabalho de examinar as reformas administrativas levadas a efeito no País verificará que, salvo raras e honrosas exceções, empreendimentos dessa natureza não se alicerçam no exato conhecimento das estruturas que se pretende modificar. As comissões de reforma, via de regra, se limitam a examinar as leis que criaram repartições e serviços, para, em seguida, mediante simples remanejamento de órgãos Ө atribuições, apresentar nova estrutura que julgam capaz de atender às necessidades governamentais.

No caso de Goiás, seguimos caminho oposto. Nossa segunda etapa de trabalho (a primeira foi a constituição e treinamento da Equipe) consistiu no completo e criterioso levantamento de todos os setores da administração, compreendendo o exame de leis, regulamentos, instruções de serviço, normas e processos de funcionamento, etc. Tudo foi visto, pesquisado, esmiuçado.

Terminando o levantamento geral, dispúnhamos de farto material e de perfeito conhecimento de todos os detalhes da 
máquina administrativa do Estado. Estávamos, pois, convenientemente aparelhados para indicar a melhor solução para cada caso.

\section{LEVANTAMENTO DE ROTINAS DE TRABALHO}

Dispensamos a êste item tratamento especial, por considerarmos que sòmente através de bem orientado levantamento de rotinas se pode escoimar de vícios e imperfeições os métodos e processos de trabalho.

Com o concurso dos membros da Equipe, realizamos paciente estudo de todos os processos que tramitam pelas repartições estaduais. A seguir, para cada tipo de processo, confeccionamos um fluxograma. Este foi detidamente examinado, e em conseqüência, procedeu-se à racionalização das rotinas de trabalho, com a eliminação de tôdas aquelas consideradas dispensáveis.

Para se ter uma idéia da economia de tempo, esfôrço humano, material e dinheiro, resultante desta providência, basta dizer que processos que, em sua tramitação do protocolo (ponto de partida) ao arquivo (ponto de chegada), registravam 36 operações, depois de simplificados passaram a apresentar apenas 12 etapas no mesmo percurso.

\section{REESTRUTURAÇÃO DA ADMINISTRAÇĀO ESTADUAL}

A administração goiana era constituída de órgãos criados em épocas diferentes, com atribuições não raro paralelas ou conflitantes, sem exato sentido de conjunto.

A estrutura das Secretarias de Estado encontrava-se inteiramente divorciada das reais exigências administrativas $e$ primava pela completa desuniformidade. Algumas estavam organizadas à base de "departamentos"; outras de "serviços"; $e$ outras ainda de "seções".

Muitas atribuições legais não eram executadas porque a prática havia demonstrado sua inutilidade. Outras eram executadas de fato, embora a legislação fôsse inteiramente omissa a respeito.

Com base nas pesquisas e levantamentos que efetuamos em tôda a administração, pudemos fixar uma estrutura capaz de satisfazer as necessidades da época, de vez que fôra alicerçada na exata divisão do trabalho governamental.

Tal estrutura foi aprovada pela Lei no 1.370 , de 9 de novembro de 1956, cujo artigo primeiro dispôs que a administra- 
ção pública estadual passaria a ser constituída dos seguintes órgãos e serviços:

I - Conselho Superior de Planejamento e Coordenação.

II - Secretarias de Estado:

- Secretaria do Interior e Justiça;

- Secretaria da Segurança Pública;

- Secretaria da Fazenda;

- Secretaria da Educação e Cultura;

- Secretaria da Saúde e Assistência;

- Secretaria da Agricultura, Indústria e Comércio;

- Secretaria de Viação e Obras.

III - Órgãos e serviços diretamente subordinados ao Governador:

- Secretaria do Govêrno;

- Procuradoria-Geral de Justiça;

- Consultoria Jurídica do Estado;

- Departamento do Serviço Público;

- Departamento Central do Material;

- Departamento Estadual de Estatística;

- Departamento Estadual de Imprensa;

- Polícia Militar.

IV - Autarquias:

- Departamento de Estradas de Rodagem de Goiás (DER-GO);

- Loteria do Estado de Goiás.

A lei mencionada adotou, como princípios orientadores de sua sistemática:

- a fixação de uma estrutura orgânica para tôda a administração;

- a completa reestruturação das Secretarias de Estado, órgãos diretamente subordinados ao Governador e entidades autárquicas;

- criação dos órgãos considerados indispensáveis e extinção daqueles reputados inúteis ou antieconômicos; 
- redução ao mínimo possível do número de órgãos diretamente subordinados ao Governador e aos Secretários de Estado;

- inclusão na lei apenas da estrutura básica, transferindo-se as subdivisões para os regimentos e regulamentos a serem baixados;

- criação do Conselho Superior de Planejamento e Coordenação, com atribuições de planejamento, coordenação geral e elaboração orçamentária;

- inclusão de dispositivo estabelecendo, expressamente, que os dirigentes de órgãos e serviços das Secretarias de Estado são funcionários da confiança imediata dos respectivos Secretários.

\section{ADMINISTRAÇÃO DO MATERIAL}

A administração do material, em Goiás, estava a cargo de uma simples divisão, localizada na Secretaria da Fazenda.

Desprovida de recursos humanos e materiais, e não contando com uma estrutura condizente com as responsabilidades que era chamada a desempenhar, o funcionamento dessa divisão se mostrava tão precário que a centralização das compras era simples ficção. Na prática, cada repartição comprava diretamente os materiais de que necessitava, de forma pouco econômica e quase sempre sem concorrência pública.

Por outro lado, a administração do material era regulada por leis incompletas e antiquadas, promulgadas em épocas em que os conhecimentos sôbre o assunto estavam longe de consolidar-se.

A Lei $n \div 1.405$, de 29 de novembro de 1956, procurou disciplinar a matéria de modo que atendesse aos interêsses do Estado. Criou o Departamento Central do Material (DCM), diretamente subordinado ao Governador, atribuindo a êsse órgão competência para, com exclusividade, efetuar tôdas as aquisições de materiais permanentes e de consumo, salvo casos especiais, de comprovada e inadiável necessidade, quando o Departamento poderia delegar competência para a compra direta de materiais em determinados locais.

Até o dia 31 de janeiro de cada ano, todos os órgãos da administração deveriam encaminhar seus programas de aquisição ao DCM, cabendo a êste elaborar o plano geral de compras em grandes quantidades, segundo as conveniências e as disponibilidades financeiras do Estado. 
As despesas de qualquer natureza com a aquisição de material seriam adicionadas ao seu custo e empenhadas à conta da dotação orçamentária por que se fizesse a compra.

A centralização das compras oferece indiscutiveis vantagens, mas às vêzes é acusada de contribuir para tornar moroso - processo de abastecimento das repartições. Para contornar êsse inconveniente, criou-se um fundo rotativo destinado à aquisição de materiais para estoque, bem como os de pronto pagamento.

Fornecido à repartição requisitante o material adquirido com recursos do Fundo, empenhar-se-ia em seguida, à conta do crédito próprio, importância correspondente, a título de reposição.

O diretor do DCM prestaria contas à Secretaria da Fazenda do movimento do Fundo Rotativo, através de balancetes mensais e documentos comprobatórios das despesas efetuadas, competindo ao órgão técnico daquela Pasta verificar a exatidão dos balancetes em confronto com a documentação, quando do levantamento das contas do referido titular.

No caso de uma repartição recusar o material adquirido pelo DCM, com base em sua diversidade do constante do programa de aquisição, seria o mesmo arrolado como patrimônio do Estado e poderia ser fornecido a outro órgão que dêle necessitasse, revertendo a favor do Fundo Rotativo o valor correspondente. Nesta hipótese, o pagamento do material correria, até o seu fornecimento a outro órgão, por conta do Fundo Rotativo.

A lei disciplinou, com clareza e exatidão, as diferentes fases da administração do material, tais como a concorrência, a coleta de preços, o julgamento da concorrência, o adiantamento, a requisição, a entrega, a aceitação, o recebimento, as penalidades aplicáveis aos fornecedores inadimplentes, a conservação e recuperação do material, etc.

Merece referência especial o capítulo relativo ao adiantamento, no qual foram introduzidas salutares inovações.

O fornecimento de adiantamentos, que antes poderia ser feito a qualquer funcionário, ficou restrito apenas àqueles que gozassem de estabilidade, como medida acauteladora dos interêsses da Fazenda pública.

Dilatou-se o prazo para aplicação do adiantamento, de 60 para 90 dias, proibindo-se sua aplicação em exercício diferente daquele em que foi concedido. 
Foi sensivelmente melhorado e simplificado o processo de recebimento, incluindo-se, entre outras modificações, a que facultava a um funcionário receber o terceiro adiantamento, desde que estivesse liquidada a prestação de contas de um dos dois anteriormente recebidos.

A lei conferiu ao DCM competência para examinar, prèviamente, a prestação de contas dos adiantamentos relativos a material, do ponto de vista econômico, financeiro, administrativo, contábil e moral, emitindo a respeito parecer circunstanciado, o qual serviria de fundamento para que o Tribunal de Contas julgasse a sua aplicação.

Se o julgamento daquela Côrte reconhecesse a existência de quaisquer irregularidades, o diretor do DCM ou a autoridade a que estivesse subordinado o responsável aplicaria a penalidade cabível, propondo a quem de direito, imediatamente, a imposição de penas que escapassem à sua alçada. Punia-se com excepcional rigor, isto é, com penas iguais às aplicáveis ao responsável pelo adiantamento, a omissão dolosa ou culposa da autoridade a quem competia punir ou providenciar a punição das faltas apuradas.

Como se vê, procurou-se armar o Tribunal de Contas de meios legais para apurar os atos praticados por funcionários na movimentação de dinheiros públicos, não sòmente do ponto de vista formal, como rotineiramente ocorre, mas sobretudo quanto aos aspectos morais da realização da despesa.

Outra inovação de grande alcance refere-se à forma de registro dos atos relativos à administração do material, fonte de eternos descontentamentos e um dos motivos do encarecimento dos materiais vendidos ao serviço público. A lei determinou que, quando não houvesse determinação expressa, o registro dos processos de aquisição de material seria sempre posterior.

Finalmente, para garantir o pleno e correto funcionamento do sistema, estabeleceu-se que seriam convidados um representante do comércio e outro da indústria para participarem das comissões de concorrências.

\section{ADMINISTRAÇÃO DO PESSOAL}

A situação do funcionalismo de Goiás era caótica. Embora o problema houvesse preocupado os governos anteriores, a multiplicidade de leis que dispunham sôbre a matéria prejudicou a unidade dos sistemas e das soluções intentadas. 
Numerosos funcionários, a despeito de exercerem funções absolutamente idênticas, percebiam retribuições diferentes. Outros ocupavam cargos de igual denominação e vencimentos, mas desempenhavam atribuições inteiramente diversas. Outros ainda desempenhavam funções que não haviam sido legalmente criadas.

Não havia, pois, um plano de classificação de cargos. Inexistia, igualmente, sistemas de recrutamento, seleção, aperfeiçoamento, promoções, incentivos. Na realidade, tudo estava por fazer.

A Lei $n$ ? 1.434, de 12 de outubro de 1956, elaborada pela Equipe da Reforma, criou o Quadro Único do Estado e aprovou - plano de classificação de cargos e revisão dos níveis de vencimentos dos servidores estaduais.

Salvo as exceções previstas na Constituição, todos os cargos do serviço civil foram abrangidos pela classificação, que incluía, como elementos principais, o cargo, o grupo de ocupação e o serviço.

Na conceituação da lei, "cargo é o conjunto de atribuições, deveres e responsabilidades cometidos a um funcionário, respeitadas as características de criação por lei, denominação própria, número certo e pagamento pelos cofres do Estado."

"Grupo de Ocupação é o conjunto constituído de cargos de atividades profissionais correlatas ou afins, escalonados segundo a natureza dos respectivos trabalhos ou os ramos de conhecimentos aplicados no seu desempenho."

Os Serviços, em número de sete, abrangiam os seguintes grupos de atividades:

I - Administrativo e Fiscal (AF)

II - Artífice (Art)

III - Educação (E)

IV - Policial (P)

$V$ - Técnico-Profissional (TP)

$\mathrm{VI}$ - Técnico-Científico (TC)

VII - Conservação, Transporte e Transmissão (CTT)

De acôrdo com o sistema adotado, cada cargo se compõe das iniciais do serviço a que pertence, do número do grupo de ocupação dentro do serviço, do número indicativo da posição 
do cargo no grupo de ocupação, bem como do padrão de vencimento e respectiva classe.

Atribuiu-se competência ao Poder Executivo para especificar, para cada cargo efetivo, as atribuições típicas, as características especiais, os requisitos para provimento e as linhas gerais de acesso. As atribuições dos cargos em comissão e das funções gratificadas constariam dos regimentos das repartições.

As tabelas anexas à lei fixaram, em caráter provisório, os padrões de vencimento para os cargos e funções gratificadas. Cada cargo deveria ter um vencimento-padrão estabelecido em razão dos deveres e responsabilidades a êle inerentes. Excetuados os cargos em comissão e as funções gratificadas, o vencimento-padrão teria uma progressão no tempo, por classe, na forma prevista nas tabelas. Assim, ao término de cada período de 730 dias de efetivo exercício, conceder-se-ia ao funcionário efetivo o avanço de uma classe no respectivo padrão de vencimento.

Nenhum extranumerário poderia perceber salário superior ao vencimento da classe inicial de cargo de funções correlatas, salvo no caso de admissão para serviços especializados de breve duração, e para as especializações das profissões correspondentes aos grupos 1,2 e 3 do Serviço Técnico-Científico.

Ao pessoal do Fisco, sujeito a regime especial de remuneração, vedou-se o exercicio de qualquer função estranha à fiscalização e arrecadação de rendas.

A nomeação para cargo de provimento efetivo ficou condicionada à prévia habilitação em concurso. $\mathrm{E}$, com relação aos interinos, a lei foi extremamente severa, pois, além de negarIhes efetivação, estabeleceu que a condição de interinidade só cessaria com a nomeação do interessado em caráter efetivo, após habilitação em concurso público. E ainda mais: foi abolida a nomeação interina, exceto para o magistério, para o Fisco e para o setor de relações públicas, tendo em vista a impossibilidade da imediata realização de concursos para essas funções, nas quais existiam vagas que não poderiam deixar de ser preenchidas, sem graves prejuízos para a administração.

A lei cercou de especiais cautelas a administração do Plano, que ficou a cargo do Departamento do Serviço Público. A alteração, extinção, supressão ou transformação de cargos ou de funções só seriam examinadas pelo Chefe do Executivo 
quando convenientemente fundamentadas e justificadas pelas repartições proponentes, e a êle encaminhadas com parecer do DSP.

\section{ADMINISTRAÇÃO FINANCEIRA}

Dada a exigüidade do espaço de que dispomos, não poderíamos relatar com minúcias as inúmeras providências adotadas no sentido de remodelar e modernizar o aparelhamento fazendário, tornando-o capaz de executar eficientemente suas importantes funções. Destacamos nesse setor apenas a regulamentação do pagamento de subvenções, auxílios e contribuições, por se tratar de assunto de interêsse geral.

A concessão de tais benefícios, quer pelo vulto dos recursos fornecidos, quer pelos abusos comumente verificados em sua aplicação, deve merecer exame cuidadoso por parte do poder público.

Ainda estão na memória de todos as lamentáveis conclusões a que chegou a Comissão de Fiscalização Financeira da Câmara dos Deputados, em relatório recentemente divulgado. As averiguações levadas a efeito por aquêle órgão técnico revelaram a existência de fatos verdadeiramente chocantes. Segundo publicação feita no Jornal do Brasil, de 19-7-70, " $30 \%$ das instituições subvencionadas pelo Orçamento federal de 1966 não existiam, não funcionavam, não são localizáveis, são irregulares ou funcionam precàriamente". Nada menos de 764 entidades jamais existiram e no entanto vinham sendo regularmente contempladas com subvenções orçamentárias.

Muito embora em Goiás não se houvesse constatado a ocorrência de casos de maior gravidade, impunha-se, como medida acauteladora, a regulamentação do pagamento e prestação de contas dos auxílios e subvenções anualmente concedidos através de dotações orçamentárias e dos lucros da Loteria do Estado.

Com base em expedientes que Ihe submetemos, o Governador baixou o Decreto n? 1.096, de 11 de agôsto de 1955, disciplinando o pagamento dos auxílios e contribuições destinados a entidades privadas.

De conformidade com o disposto naquele diploma legal, as pessoas jurídicas beneficiadas com tais recursos deveriam enCaminhar os pedidos de pagamento às repartições competentes até o dia 15 de junho de cada ano. 
Quando se tratasse de auxílios, subvenções e contribuições para obras, os pedidos de pagamento seriam instruídos com os seguintes documentos:

- orçamentos, plantas e especificações;

- cópia autêntica do contrato firmado para execução das obras;

- indicações sumárias sôbre a rentabilidade ou interêsse social dos empreendimentos.

No caso de contribuições com destinação diferente da constante do item anterior, os pedidos de pagamentos deveriam ser acompanhados de minucioso plano de aplicação.

As entidades beneficiadas com auxílios ou subvenções deveriam fazer rigorosa prestação de contas dos fundos recebidos, sem o que não se lhes seriam feitos novos pagamentos.

Para o pagamento das ajudas governamentais, foi estabelecida a seguinte ordem de prioridade:

- manutenção de hospitais, ambulatórios e postos de saúde;

- manutenção de estabelecimentos de ensino;

- obras rodoviárias e de eletricidade;

- serviços de água e esgôto;

- prédios e aparelhamento escolares;

- prédios e aparelhamento de hospitais, ambulatórios e postos de saúde;

- atividades escolares e esportivas;

- atividades assistenciais não compreendidas nas alíneas anteriores.

Finalmente, para afastar qualquer possibilidade de favoritismo, o Decreto determinou que os pedidos fôssem processados, encaminhados e decididos pela rigorosa ordem de entrada no protocolo da repartição, com exceção apenas dos processos incompletos ou com documentação deficiente, caso em que seriam devolvidos para a devida complementação.

\section{REORGANIZAÇÃO DO DEPARTAMENTO DE ESTRADAS DE RODAGEM DE GOIÁIS (DER-GO)}

O Departamento de Estradas de Rodagem de Goiás (DERGO), pela complexidade de suas atribuições, pela natureza dos trabalhos que executa, pelo número de pessoas que emprega 
e especialmente pelo vulto dos recursos que movimenta, teria que constituir um capítulo especial no contexto da reforma administrativa.

Dado o caráter sintético dêste artigo, deixaremos de focalizar aqui os trabalhos desenvolvidos na reestruturação desta importante autarquia. Discutiremos com pormenores apenas a reorganização do quadro de pessoal. Antes, porém, faremos ligeiras referências a algumas inovações introduzidas no setor financeiro, por serem as mesmas reveladoras da constante preocupação da reforma de resguardar a boa aplicação dos dinheiros públicos.

Com tal objetivo, além de manter e ampliar as atribuições do Tribunal de Contas no tocante às delegações de contrôle junto às autarquias estaduais, incluímos na lei dispositivo segundo o qual os fundos movimentados pelo DER-GO seriam fiscalizados, em caráter permanente, por representante do Estado, de livre nomeação e exoneração do Chefe do Executivo. Surgia assim, no plano estadual, cremos que pela primeira vez, uma tentativa de institucionalização das auditorias financeiras, princípio até hoje ainda não inteiramente consagrado na administração pública. $\mathrm{E}$ a lei foi além. Estabeleceu que as autarquias estaduais não poderiam eximir-se da prestação, à Assembléia Legislativa do Estado, de quaisquer informações administrativas ou financeiras relativas ao exercício de suas atividades.

Fechado êste breve parêntesis, vamos analisar o que se fêz no setor do pessoal.

O Departamento de Estradas de Rodagem de Goiás não possuía pròpriamente quadro de pessoal. As admissões eram feitas para as Divisões ou Seções, em número ilimitado, a juízo da Diretoria. Não fôra adotado um plano de remuneração para OS servidores, motivo por que funcionários ocupantes de funções de igual denominação percebiam salários inteiramente diversos.

A escala de vencimentos abrangia nada menos de 35 referências, distribuídas de forma arbitrária. À referência inicial correspondia o pagamento de mil cruzeiros antigos; à final, doze mil cruzeiros antigos.

A ausência de um escalonamento dos cargos e funções, pois as diferenças salariais entre um cargo e outro eram insignificantes, impedia a adoção de adequado plano de promoções.

Também foram instituídas funções gratificadas sem a observância de quaisquer critérios. As gratificações oscilavam 
entre 200 e 3.000 cruzeiros antigos. Funções com o mesmo nível de deveres e responsabilidades contavam com retribuições diferentes.

Os servidores eram recrutados pelo critério da livre escoIha, sem quaisquer averiguações sôbre suas aptidões para 0 exercício do cargo.

Não se cogitara da criação do cargo de Diretor-Geral do Departamento. Como a nomeação para essas funções normalmente recaía em funcionário da própria autarquia, a questão era resolvida mediante a fixação para o mesmo de uma gratificação. Entretanto, se fôsse escolhido um elemento estranho aos quadros da repartição, o Govêrno teria dificuldades de resolver o problema de sua remuneração.

Com a completa reorganização do quadro de pessoal do DER-GO, todos êsses inconvenientes foram sanados. As inovações nesse setor compreenderam:

- a exigência de prova pública de caráter competitivo para ingresso em qualquer série funcional;

- a constituição de séries funcionais integradas por funções de igual denominação;

- o escalonamento das séries funcionais de modo que permitisse o estabelecimento de um razoável sistema de promoções;

- a redução de 35 para 15 do número de referências salariais;

- a criação do cargo isolado de provimento efetivo de Diretor-Geral;

- o escalonamento das funções gratificadas com base nas atribuições, deveres e responsabilidades;

- o preenchimento de $50 \%$ das vagas existentes na referência inicial de uma série funcional, mediante a promoção dos ocupantes da referência final da série funcional auxiliar;

- o enquadramento do pessoal nas novas tabelas pela rigorosa ordem de merecimento a ser apurado através de critérios tanto quanto possível objetivos, por uma comissão composta pelo Diretor-Geral, pelo Diretor Administrativo e por um representante do Conselho Rodoviário do Estado. 


\section{LOTERIA DO ESTADO DE GOIASS}

Pela sua relevante participação nos programas de auxílio às atividades assistenciais, culturais e esportivas em todo o território goiano, a Loteria do Estado de Goiás foi alvo de atenções especiais por parte da Equipe da Reforma Administrativa.

Além da revisão de sua estrutura e dos seus métodos de trabalho, planejamos um esquema de distribuição dos lucros daquela entidade, o qual foi aceito e constou da lei que reorganizou a administração estadual. Tal esquema previa que, deduzidos $20 \%$ para constituição do fundo de reserva e garantia, os $80 \%$ restantes dos lucros auferidos em cada exercício seriam rateados da seguinte forma:

a) $25 \%$ em auxílios à maternidade e à infância;

b) $30 \%$ no fomento de atividades culturais e construção de praças de esporte;

c) $25 \%$ em auxílios a instituições de saúde e assistência;

d) $20 \%$ em auxílio às caixas escolares.

$\mathrm{Na}$ distribuição dos recursos, $1 / 3$ de cada percentagem deveria ser obrigatòriamente aplicado na Capital e $2 / 3$ no interior do Estado, com exceção do item "d", cuja aplicação far-se-ia, equitativamente, entre tôdas as caixas escolares existentes em Goiás.

\section{ALGUNS EXEMPLOS DE RACIONALIZAÇÃO}

\section{ADMINISTRATIVA}

Seria evidentemente impossível, no curso desta exposição, relatarmos em detalhe as inúmeras inovações e modificações que inserimos na máquina administrativa estadual. Nosso espaço não comportaria trabalho dessa natureza e, por isso, nos limitamos a oferecer uma visão panorâmica do nosso trabalho.

Consideramos indispensável, porém, apontar aqui pelo menos dois exemplos concretos de racionalização administrativa, por constituírem os mesmos atestados eloqüentes de quanto se pode fazer no sentido de desemperrar a máquina do Estado e reduzir os seus custos operacionais. 


\section{COLETORIA DAS RENDAS INDUSTRIAIS}

Em 1956 (e em parte até agora), em Goiânia, os serviços de água, esgôto, telefone e pavimentação eram executados diretamente pelo Govêrno do Estado, em virtude de a Prefeitura Municipal não dispor de condições para explorá-los.

Cada um dêsses serviços funcionava em local diferente $e$ dispunha de sistema próprio de arrecadação de suas taxas.

Como o número de usuários era bastante elevado e o pagamento das taxas, efetuado em pontos diferentes e de difícil acesso, exigia muito tempo e paciência por parte daqueles que se utilizavam de tais serviços, só pequena parte conseguia pagar seus débitos. A esmagadora maioria estava sempre em atraso.

A solução encontrada para êste problema foi a criação de uma Coletoria das Rendas Industriais, que deveria funcionar como órgão centralizador da cobrança das taxas dos quatro serviços mencionados.

Nossa primeira preocupação consistiu na escolha de um local para funcionamento da nova repartição. Graças à diligente cooperação do Secretário de Viação e Obras, conseguimos uma sala ampla no pavimento térreo de um prédio situado em pleno centro de Goiânia.

Feito o levantamento da situação dos diferentes serviços, verificamos que quase tudo precisava ser mudado. Pelo sistema até então em uso, em cada um dos serviços abria-se, para cada contribuinte, uma ficha em que figuravam os elementos relativos à situação de seu débito. O preço unitário dessas fichas era, na época, de Cr\$2.200,00. Sendo superior a 24.0000 número total de usuários, as despesas com fichas ultrapassavam a casa dos $\mathrm{Cr} \$ 53.000,00$.

Planejamos uma ficha única para os quatro serviços. Num dos lados, figuravam água e esgôto; no outro, telefone e pavimentação. Com êsse nôvo tipo de ficha, em vez de 24 milheiros, eram suficientes apenas 6 milheiros, pois numa só ficha constavam os quatro serviços. O milheiro desta nova ficha custava Cr\$2.800,00. Seis milheiros importavam em $\mathrm{Cr} \$$..... $16.800,00$. Houve, portanto, só em fichas, uma economia de Cr\$ $36.000,00$.

Ainda mais. A ficha anterior era utilizada sòmente durante dois anos; a que planejamos e adotamos sê-lo-ia durante três anos. Conseguiu-se, com tal providência, economia de um ano, 
ou seja, metade do custo total das fichas anteriores, isto é, Cr\$26.400,00.

Pelo sistema antigo, tôda vez que se quisesse extrair os talões de cobrança dos quatro serviços, ter-se-ia que localizar, separadamente, a ficha de cada um dêles. Seriam quatro operações distintas.

Com a instituição da ficha única, as quatro operações de localização das fichas se reduziram a uma única operação, pois na mesma ficha constava a situação do contribuinte em relação aos quatro serviços.

A ficha única simplificou, ainda, os trabalhos de lançamento dos débitos e de preenchimento dos talões de cobrança, além de facilitar e tornar mais eficiente o contrôle do pagamento das taxas.

Pelo sistema anterior, os talões de cobrança eram extraídos no momento em que o usuário comparecia para efetuar o pagamento. Tal processo mostrou-se de todo inconveniente, pois as partes se acumulavam na repartição e eram obrigadas a suportar longas horas de espera.

No nôvo sistema, os talões eram extraídos com antecedência e arquivados por rua, de modo que, quando o interessado comparecia, para efetuar o pagamento, não havia qualquer dificuldade, pois bastava o funcionário apanhar os talões no fichário e entregá-los ao Caixa-Receber. Quanto ao Caixa, o seu trabalho se resumia em carimbar os talões, rubricá-los e entregar uma via ao contribuinte, depois de receber a importância correspondente.

As operações realizadas pelos funcionários da Coletoria com cada usuário, da sua chegada ao balcão ao momento em que efetuava o pagamento, foram estudadas, cronometradas e racionalizadas e deveriam ser executadas em menos de cinco minutos.

\section{ORGANIZAÇAOO DE PROTOCOLOS}

As Secretarias e órgãos diretamente subordinados ao GoVernador não contavam com serviços de protocolo convenientemente organizados. Com exceção das Secretarias da Fazenda da Educação e Cultura, os protocolos das demais funcionavam de modo bastante precário. Em algumas delas, o registro 
Os trabalhos da Equipe nesse setor produziram excelentes resultados, expressos em aumento de eficiência e em considerável economia de tempo, dinheiro, material, esfôrço humano e comodidade para as partes.

Número único. Pelo sistema até então adotado, os processos fichados numa Secretaria recebiam nôvo número tôda vez que se deslocavam para outra Secretaria ou órgão diretamente subordinado ao Governador. Esta prática era altamente inconveniente para as partes e para as próprias repartições, razão por que resolvemos aboli-la. Instituímos o sistema de numeração única, segundo a qual um processo percorre todos os órgãos do Poder Executivo apenas com o número que recebe no protocolo de origem.

Veremos, a seguir, os resultados obtidos com esta nova orientação. Cronometramos o tempo gasto com as operações de aposição de nôvo número em processos oriundos de outro órgão. Com cada processo, gastavam-se dois minutos. Só pela Secretaria da Fazenda passavam, anualmente, mais 10.000, vindos de outras repartições. Multiplicando-se os 10.000 processos pelos 2 minutos, tínhamos 20.000 minutos ou 333 horas, despendidos com tais operações. Só na Secretaria da Fazenda, portanto, fêz-se uma economia de 333 horas de trabalho, que poderiam ser utilizadas na realização de tarefas bem mais importantes.

Fichas de protocolo. Nos protocolos que adotavam fichários, as fichas diferiam em tamanho e nos dizeres, de uma para outra Secretaria. Via de regra, eram usadas fichas grandes, com muitos itens que não eram utilizados.

Planejamos um modêlo de ficha de tamanho igual à metade da que era anteriormente empregada e cujos dizeres foram reduzidos e simplificados. O milheiro da ficha anterior custava Cr $\$ 600,00$. O milheiro da ficha nova passou a custar apenas Cr\$300,00. Na Secretaria da Fazenda gastavam-se, por ano, aproximadamente, 40.000 fichas de protocolo. Assim, as despesas com fichas $(40.000 \times 600,00)$ eram de $\mathrm{Cr} \$ 24.000,00$. Com a adoção do nôvo modêlo, que custava exatamente a metade do anterior, as mesmas despesas passaram a-ser apenas de $\mathrm{Cr} \$ 12.000,00(40.000 \times 300,00)$. Houve, portanto, apenas naquela Secretaria, uma economia anual de $\mathrm{Cr} \$ 12.000,00 \mathrm{com}$ fichas de protocolo.

Economia de fichários. Pelo sistema antigo, cada gaveta de fichário comportava apenas duas fileiras de fichas. Com a redução do tamanho das fichas, cada gaveta passou a caber 
três fileiras. Sòmente no fichário da Secretaria da Fazenda, houve uma economia de 27 gavetas, o equivalente a 4 fichários. Sendo o preço de um fichário, àquela época, estimado em Cr\$ 7.000,00, houve no protocolo em questão economia de 4 fichários, ou sejam, Cr\$28.000,00.

Fazenda:

Resumo da economia feita no protocolo da Secretaria da

Cr\$

333 horas de trabalho à base de $\operatorname{Cr} \$ 10,00$ a hora .................... $3.330,00$

40 milheiros de fichas a $\mathrm{Cr} \$ 300,00$ o milheiro .................... $12.000,00$

4 fichários de aço a Cr $\$ 7.000,00$ cada $28.000,00$

TOTAL:

$43.330,00$

Objetar-se-á que as economias aqui apresentadas são até certo ponto inexpressivas. Em parte a crítica é procedente. Mas, se somássemos as reduções verificadas nos diferentes órgãos, concluiríamos que os resultados foram sem dúvida compensadores.

\section{CÓDIGO DE ÉTICA FUNCIONAL}

Reafirmamos aqui o que já dissemos em outra oportunidade. Numa reforma de base como a que fizemos em Goiás, cujos aspectos principais estamos focalizando neste artigo, paralelamente às modificações de estrutura e à adoção de métodos racionais de trabalho, não se poderia deixar de tentar obter completa reforma de mentalidade. Seria desejável que se desse aos servidores públicos per-
feita noção dos seus deveres, atribuições e responsabilidades, para que cada um pudesse compreender a relevante missão social que lhes cabe desempenhar, passando a exercer suas funções de forma satisfatória, com um mínimo de atrito e descaso.

Dentre as providências que foram estudadas com êsse objetivo destaca-se, pela sua importância e originalidade, o Código de Ética Funcional, que chegou a ser elaborado, mas que por vários motivos não pôde ser pôsto em prática.

As disposições do mencionado Código se distribuíam por cinco capítulos. O primeiro continha a parte fundamental e verSava sôbre a ética dos funcionários em geral. O segundo tratava 
da conduta do chefe em relação aos seus superiores, ao público e aos seus subordinados. O terceiro referia-se à ética dos funcionários burocráticos para com seus superiores, seus colegas e o público. O quarto tratava da ética dos policiais. E o quinto, finalmente, se relacionava com a ética dos contínuos e demais funcionários subalternos.

Em todos os capítulos, procurou-se dar ênfase especial aos deveres dos funcionários para com o público, incutindo-lhes a noção de que êste, na qualidade de contribuinte e financiador da máquina do Estado, deveria ser tratado com respeito e com a máxima consideração.

\section{TÉCNICOS PARA A ADMINISTRAÇÃO ESTADUAL}

A implantação de uma reforma encontra enormes dificuldades, entre as quais se avulta a deficiência de pessoal tècnicamente qualificado. Isto não ocorre só nos Estados menos desenvolvidos, mas até mesmo em São Paulo e na Guanabara, que já dispõem de razoáveis mercados de trabalho.

Conhecendo muito bem tal situação, procuramos sugerir uma série de medidas tendentes a melhorar o preparo técnico do funcionalismo goiano, com o fim de se obter maior rendimento e melhor participação nos trabalhos.

Além da instituição do Curso de Informações Policiais, de vários cursos de treinamento, do Curso de Aperfeiçoamento de Diretores de Estabelecimentos de Ensino, e da criação, no Departamento do Serviço Público, de uma Divisão de Seleção e Aperfeiçoamento, o Govêrno celebrou convênio com a Escola Brasileira de Administração, da Fundação Getúlio Vargas, para formação de 40 técnicos de administração e para o treinamento intensivo de funcionários estaduais, através de cursos e estágios naquele estabelecimento de ensino especializado.

\section{REFORMA PIONEIRA}

Qualificamos de pioneira, no início dêste artigo, a reforma administrativa de Goiás. E esta afirmativa é rigorosamente exata, pois, em 1956, introduzimos na administração daquele Estado várias inovações que, só muitos anos mais tarde, seriam incluídas na própria administração federal.

Além do registro posterior de despesas com material, da instituição do princípio das auditorias financeiras, da formulação de um esquema de classificação de cargos com numerosos pontos de contato com o mais tarde aprovado pela Lei Federal 
n: $3.780 / 60$, propusemos a criação do Conselho Superior de Planejamento e Coordenação, semelhante aos órgãos congêneres surgidos ùltimamente nos Estados e na União.

Entre as principais atribuições do referido Conselho, incluíam-se a elaboração do plano quadrienal de desenvolvimento, a organização da proposta orçamentária, o contrôle administrativo da execução do orçamento, a coordenação geral das atividades administrativas, o sistema de estímulos e incentivos à iniciativa privada etc.

Como órgão deliberativo, para exame da proposta orçamentária, coordenação das atividades governamentais e contrôle administrativo da execução do orçamento, o Conselho funcionaria sob a presidência do Governador e seria integrado pelos Secretários de Estado e dirigentes de órgãos diretamente subordinados. Como órgão deliberativo, para exame e aprovação do plano de desenvolvimento, e consultivo nos demais casos, sua constituição seria bastante ampliada, pois dêle passavam a participar o Vice-Governador, o Presidente do Conselho Rodoviário, um delegado de cada um dos partidos políticos com representação na Assembléia Legislativa, um delegado dos diretores e gerentes de estabelecimentos bancários, assim como um delegado de cada uma das seguintes pessoas jurídicas de direito privado: Associação Comercial, Federação das Indústrias, Federação do Comércio, Federação das Associações Rurais, Sociedade Goiana de Pecuária e Clube de Engenharia de Goiás.

O Conselho teria uma Secretaria Executiva, com uma Divisão de Planejamento, uma Divisão de Coordenação e Contrôle e uma Divisão de Orçamento, além de uma Assessoria Técnica.

Os planos de desenvolvimento teriam a duração de quatro anos, de sorte que o último ano de sua execução coincidiria sempre com o primeiro da gestão do nôvo Governador. O Chefe do Executivo empossado executaria a última etapa do plano deixado por seu antecessor e promoveria a confecção de nôvo plano, cuja última etapa seria executada pelo seu sucessor. Dessa forma, imprimir-se-ia sentido de planejamento às atividades governamentais, assegurando-se, por outro lado, a indispensável continuidade administrativa.

A proposta orçamentária seria feita com base no plano de trabalho. Cada orçamento corresponderia, assim, a uma etapa do plano. Conseguir-se-ia, dêsse modo, a racional utilização dos recursos financeiros disponíveis, os quais seriam canalizados para empreendimentos seletivos e diretamente relacionados com 0 desenvolvimento econômico do Estado. 


\section{CONCLUSÃO}

Em discurso pronunciado na Câmara dos Deputados (Diário do Congresso Nacional de 7-2-56), o então Deputado WAGNER ESTELITA CAMPOS expendeu as seguintes considerações a respeito da Reforma Administrativa de Goiás:

"Sr. Presidente, em minha viagem recente a Goiânia, tive ocasião de entrar em demorado contato com a equipe que, sob a direção de meu colega Joaquim $\mathrm{Ne}-$ ves Pereira, vem realizando, por determinação do $\mathrm{Sr}$. Governador, a reforma administrativa do Estado. Tão impressionado fiquei com os respectivos trabalhos que solicitei àquele prezado colega - cujo nome tive a honra de indicar ao Governador - me fornecesse 0 relatório de suas atividades a fim de que as pudesse comunicar à Câmara. É o que ora faço, valendo-me da cópia do minucioso trabalho que acaba de ser apresentado ao Diretor-Geral do DASP.

O Govêrno do Estado de Goiás, que se vem destacando através de realizações de grande alcance, tais como, por exemplo, a construção da Central Elétrica de Cachoeira Dourada e das diversas providências que visam facilitar a próxima transferência, pela União, da Capital da República, verá inscrita, como um dos seus pontos altos, a reforma administrativa ora em franco desenvolvimento.

Trata-se de empreendimento digno de figurar nas páginas dos nossos Anais, para conhecimento dos congressistas e dos estudiosos; e estou certo de que êle igualmente impressionará os responsáveis pelos governos das diversas unidades federativas, em seus diferentes níveis.

O plano de trabalho abrange, principalmente, a reestruturação geral dos órgãos integrantes do Poder Executivo, a reestruturação geral dos quadros de pessoal, a reforma da administração financeira e a reorganização do sistema da administração do material .

Não seria possível, nesta breve comunicação, assinalar todos os aspectos fundamentais da reforma. Desejo apenas apontar, para que se tenha uma idéia de sua importância, a proposta da instituição de um Conselho Superior de Planejamento e Coordenação (que terá o encargo de elaborar o plano de trabalho governamental a longo prazo e confeccionar a proposta orçamen- 
tária de tal forma que os planos parciais correspondam aos diversos exercícios financeiros, dando assim caráter racional à feitura da lei de meios), assim como a racionalização dos processos de trabalho, precedida de um levantamento de rotina, com o objetivo de eliminar as consideradas desnecessárias e fundir aquelas que sejam semelhantes ou correlatas.

Êstes dois aspectos traduzem dois propósitos até hoje não concretizados em nossa Administração, nem mesmo na Federal, com caráter sistemático e geral.

Iniciativas desta natureza representam um estímulo e e um confôrto para todos nós, os estudiosos da administração pública, notadamente num momento em que, como o atual, assistimos o melancólico desfecho do Plano de Classificação de Cargos e Revisão dos Níveis de Vencimento dos Servidores Federais."

O caráter pioneiro do trabalho que efetuamos em Goiás fica mais uma vez evidenciado pelas generosas palavras aqui transcritas, proferidas no Plenário da Câmara dos Deputados pelo Dr. WAGNER ESTELITA CAMPOS, atual Ministro do Tribunal de Contas da União.

Com o concurso de uma equipe constituída de elementos da melhor categoria moral e profissional, e graças ao decidido apoio do Chefe do Executivo goiano, tentamos realizar naquele Estado uma reforma global da administração. Se não conseguimos atingir plenamente o nosso objetivo, nem por isso nutrimos qualquer sentimento de frustração, pois temos a consciência de que fizemos o que era humanamente possível e de que muita coisa restou daquele excepcional esfôrço de organização.

Ao trazermos para as páginas da Revista do Serviço Público uma síntese de nossa experiência, não nos move outro propósito senão o de oferecermos subsídios aos estudiosos da matéria, contribuindo assim, embora modestamente, para o aperfeiçoamento das instituições administrativas do País. 
